\title{
Mycoplasma pneumoniae: now in the focus of clinicians and epidemiologists
}

E Jacobs (enno.jacobs@tu-dresden.de) ${ }^{1}$

1. Dresden University of Technology, Medical Faculty Carl Gustav Carus, Institute of Medical Microbiology and Hygiene, Dresden, Germany

Several northern European countries have experienced outbreaks of Mycoplasma pneumoniae infection in 2010 and 2011, as described in recent reports and in this issue. Such outbreaks appear with regular periodicity and have occupied clinicians and epidemiologists for many years.

Some 50 years ago, Chanock et al. [1] described an artificial medium that enabled the identification of the aetiological agent of an atypical pneumonia first reported 20 years earlier, which was first described as pleuropneumonia-like organisms (PPLO) and renamed as Mycoplasma pneumoniae [2]. More recently, genome analysis has revealed the bacterium's limited metabolism and biosynthesis of carbohydrates, proteins, nucleic acid and lipids, showing that the agent is well adapted to its only host, humans. We are, however, still unable to mimic the natural environment of $M$. pneumoniae: faster growth in culture media is needed for diagnostic purposes. It takes more than 10 days - in fact often up to three weeks - to grow M. pneumoniae from respiratory specimens taken from patients with an interstitial pneumonia. The organism can be cultured from samples taken in the acute phase of the infection, but because of the length of time needed, culture techniques have not been established in most bacteriological laboratories.

Lind et al. were the first in Europe to identify M. pneumoniae infection by detecting increases in M. pneumoniae-specific antibody titre, based at that time on cold agglutinin and complement fixation tests [3].

One striking aspect of $M$. pneumoniae infection is the periodicity of epidemics. The Danish seroepidemiological study of Lind et al., conducted over a 50-year period, showed between 1958 and 1973 an almost regular pattern of epidemics every four and a half years [3]. The authors suggested that herd immunity lasts about four years (range: 2-10) before people are again susceptible to infection with $M$. pneumoniae.
A prospective study of 4,532 outpatients in Germany aged at least 18 years with community-acquired pneumonia showed that $M$. pneumoniae was one of the major causative bacterial agents: 307 patients (6.8\%) were $M$. pneumoniae-positive by real-time-PCR and/or positive for M. pneumoniae-specific IgM antibodies [4]. Some $72 \%$ of the patients with $M$. pneumoniae infection had only a mild pneumonia: this, combined with the number of days of hospitalisation required, might suggest a less severe pneumonia outcome in $M$. pneumoniae infections.

In many countries, clinicians had to treat patients with community-acquired pneumonia due to M. pneumoniae infection empirically during the whole acute phase because of the delay in the increase of antibody titres or because of the time needed for culture. Epidemiological studies were hampered for a long time because of these diagnostic difficulties. Consequently, M. pneumoniae was more or less ignored or in many countries 'a black box' in epidemiology because of the lack of diagnostic results. The situation changed, however, with the introduction of several molecular techniques, especially real-time $P C R$, into routine diagnosis [5]. Another advance has been the characterisation of different $M$. pneumoniae genotypes circulating in the human population. Clinical strains can be differentiated on basis of differences in the $\mathrm{P}_{1}$ adhesin gene or in the number of repetitive sequences at a given genomic locus using multilocus variable number tandem repeat analysis (MLVA) [6,7]. Both typing methods are not currently used routinely in epidemiological studies. However, typing will allow us to get more information about outbreaks of defined strains in different countries of Europe or even worldwide as well as information about changes in strains within a population. A long-term genotyping study from Japan [8] suggests that epidemics arise due to a change in the two main $P_{1}$ types or even of because of further variants of $P 1$ sequences, which were found recently $[9,10]$.

MLVA allows greater discrimination between $M$. pneumoniae strains because of the very variable numbers 
of repeats in the genome of different strains. It was used recently by Chalker et al. describing increased numbers of $M$. pneumoniae infections in England and Wales in 2011 and 2012 [11,12]. Outbreaks were seen in the years 1995, 1997/1998, 2002/2003, 2006 and a prepeak in 2010 before the outbreak in 2011. The peaking periods described showed all the characteristics of a M. pneumoniae epidemic, i.e. a broad 'shoulder', sometimes in two consecutive epidemic years with slightly fewer cases in summer than in later autumn and winter. Such a pattern was shown in Denmark for 2010 and 2011 [13].

Typing should answer the question, if such peaks could be attributed to different or to the same genotypes. Interestingly, Chalker et al. showed a small peak in 2010 before the outbreak in 2011. These findings suggest it will be necessary in the future to type more often strains from different countries and periods to answer the question of whether there is common epidemic spread of distinct genotypes in different countries of Europe. It is as yet unknown whether the recent epidemics in northern Europe [13-17] are caused by a common type strain.

Macrolide resistance has been described recently in Asia, with up to $90 \%$ of $M$. pneumoniae strains being resistant [18]. In the reports from the countries in northern Europe, no macrolide resistance was found in the tested strains except for Denmark, where $0.9 \%$ to $2.9 \%$ of strains were resistant This is in accordance with data from France and Germany, where about 3\% of strains were found to be resistant $[19,20]$. Particularly as a vaccine against $M$. pneumoniae is not yet available, macrolides - which are the only recommended therapy for children (whereas doxycycline and fluoroquinolones can be used for adults) - should be used carefully, as pointed out by Linde et al. in this issue [16]. It is not yet known whether the increased use of erythromycin in Norway at the end of 2011 [14] will induce more resistance. We should nevertheless be aware of possible macrolide resistance of $M$. pneumoniae during therapy even though this was not been seen in the paper by Uldum et al. [13]. The first two reports of emergence of macrolide-resistant $M$. pneumoniae during therapy were published last year by Cardinale et al. from Italy [21] and Averbuch et al. from Israel [22] in children with severe pneumonia. Such resistance may pose a major problem for clinicians, as certain antibiotics are not recommended for young children. In both cases, ciprofloxacin was given and the children were cured within a few days.

We now have the laboratory tools to detect M. pneumoniae within a day and also to identify possible macrolide resistance [20]. In order to aid clinicians, real-time PCR can be used, especially in the acute phase of infection, to diagnose $M$. pneumoniae in nasopharyngeal swabs or a provoked sputum [4]: this could become the gold standard for diagnosis. For more sophisticated studies, epidemiologists in Europe should come to an agreement on standard sampling and a common typing method for M. pneumoniae strains.

\section{References}

1. Chanock RM, Hayflick L, Barile MF. Growth on artificial medium of an agent associated with atypical pneumonia and its identification as a PPLO. Proc Natl Acad Sci U S A. 1962;48:41-9.

2. Eaton MD, Meiklejohn G, Vanherick W, Talbot JC. An infectious agent from cases of atypical pneumonia apparently transmissible to cotton rats. Science. 1942;96(2501):518-9.

3. Lind K, Benzon MW, Jensen JS, Clyde WA Jr. A seroepidemiological study of Mycoplasma pneumoniae infections in Denmark over the 50-year period 1946-1995. Eur J Epidemiol. 1997;13(5):581-6.

4. von Baum H, Welte T, Marre R, Suttorp N, Lück C, Ewig S.Mycoplasma pneumoniae pneumonia revisited within the German competence network for community-acquired pneumonia (CAPNETZ). BMC Infect Dis. 2009;9:62.

5. Dumke R, Jacobs E. Comparison of commercial and in-house real-time PCR assays used for detection of Mycoplasma pneumoniae. J Clin Microbiol. 2009;47(2):441-4.

6. Dégrange $S$, Cazanave $C$, Charron $A$, Renaudin $H$, Bébéar $C$, Bébéar CM. Development of multiple-locus variable-number tandem-repeat analysis for molecular typing of Mycoplasma pneumoniae. J Clin Microbiol. 2009;47(4):914-23.

7. Dumke R, Jacobs E. Culture-independent multi-locus variablenumber tandem-repeat analysis (MLVA) of Mycoplasma pneumoniae. J Microbiol Methods. 2011;86(3):393-6.

8. Kenri T, Okazaki N, Yamazaki T, Narita M, Izumikawa K, Matsuoka M, et al. Genotyping analysis of Mycoplasma pneumoniae clinical strains in Japan between 1995 and 2005: type shift phenomenon of M. pneumoniae clinical strains. J. Med Microbiol. 2008;57(Pt 4):469-75.

9. Dumke R, von Baum H, Lück PC, Jacobs E. Subtypes and variants of Mycoplasma pneumoniae: local and temporal changes in Germany 2003-2006 and absence of a correlation between the genotype in the respiratory tract and the occurrence of genotype-specific antibodies in the sera of infected patients. Epidemiol Infect. 2010;138(12):1829-37.

10. Spuesens EB, Oduber M, Hoogenboezem T, Sluijter M, Hartwig $N G$, van Rossum AM, et al. Sequence variations in RepMP2/3 and RepMP4 elements reveal intragenomic homologous DNA recombination events in Mycoplasma pneumoniae. Microbiology. 2009;155(Pt 7):2182-96.

11. Chalker VI, Stocki T, Mentasti M, Fleming D, Harrison T. Increased incidence of Mycoplasma pneumoniae infection in England and Wales in 2010: multilocus variable number tandem repeat analysis typing and macrolide susceptibility. Euro Surveill. 2011;16(9):pii=19865. Available from: http:/ www.eurosurveillance.org/ViewArticle.aspx?Articleld $=19865$

12. Chalker VJ, Stocki T, Litt D, Bermingham A, Watson J, Fleming DM, et al. Increased detection of Mycoplasma pneumoniae infection in children in England and Wales, October 2011 to January 2012 . Euro Surveill. 2012;17(6): pii=20081. Available from: http://www.eurosurveillance.org/ViewArticle. aspx?Articleld $=20081$

13. Uldum SA, Bangsborg JM, Gahrn-Hansen B, Ljung R, Mølvadgaard M, Føns Petersen R, et al. Epidemic of Mycoplasma pneumoniae infection in Denmark, 2010 and 2011. Euro Surveill. 2012;17(5):pii=20073. Available from: http:// www.eurosurveillance.org/ViewArticle.aspx?Articleld $=20073$

14. Blystad H, Ånestad G, Vestrheim DF, Madsen S, Rønning K. Increased incidence of Mycoplasma pneumoniae infection in Norway 2011. Euro Surveill. 2012;17(5): pii=20074. Available from: http://www.eurosurveillance.org/ViewArticle. aspx?Articleld $=20074$

15. Polkowska A, Harjunpää A, Toikkanen S, Lappalainen $M$, Vuento R, Vuorinen T, Kauppinen J, Flinck H, Lyytikäinen 0. Increased incidence of Mycoplasma pneumoniae infection in Finland, 2010-2011. Euro Surveill. 2012;17(5):pii=20072. Available from: http://www.eurosurveillance.org/ViewArticle. aspx?Articleld $=\mathbf{2 0 0 7 2}$

16. Linde A, Ternhag A, Törner A, Claesson BE. Antibiotic prescriptions and laboratory-confirmed cases of Mycoplasma pneumoniae during the epidemic in Sweden in 2011. Euro Surveill. 2012;17(6):pii=20082. Available from: http://www. eurosurveillance.org/ViewArticle.aspx?Articleld $=20082$

17. Lenglet A, Herrador Z, Magiorakos AP, Leitmeyer K, Coulombier D, European Working Group on Mycoplasma pneumoniae surveillance. Surveillance status and recent data for Mycoplasma pneumoniae infections in the European 
Union and European Economic Area, January 2012. Euro

Surveill. 2012;17(5):pii=20075. Available from: http://www.

eurosurveillance.org/ViewArticle.aspx?Articleld =20075

18. Zhao F, Lv M, Tao X, Huang H, Zhang B, Zhang Z, et al.

Antibiotic sensitivity of 40 Mycoplasma pneumoniae

isolates and molecular analysis of macrolide-resistant

isolates from Beijing, China. Antimicrob Agents Chemother.

2012;56(2):1108-9.

19. Pereyre S, Charron A, Renaudin H, Bébéar C, Bébéar CM. First report of macrolide-resistant strains and description of a novel nucleotide sequence variation in the $\mathrm{P}_{1}$ adhesin gene

in Mycoplasma pneumoniae clinical strains isolated in France over 12 years. J Clin Microbiol. 2007;45(11):3534-9.

20. Dumke R, von Baum H, Lück PC, Jacobs E. Occurrence of macrolide-resistant Mycoplasma pneumoniae strains in Germany. Clin Microbiol Infect. 2010;16(6):613-6.

21. Cardinale F, Chironna M, Dumke R, Binetti A, Daleno C Sallustio A, et al. Macrolide-resistant Mycoplasma pneumoniae in paediatric pneumonia. Eur Respir J. 2011;37(6):1522-4.

22. Averbuch D, Hidalgo-Grass C, Moses AE, Engelhard D, Nir-Paz R. Macrolide resistance in Mycoplasma pneumoniae, Israel, 2010. Emerg Infect Dis. 2011;17(6):1079-82. 